\title{
C vitamini, E vitamini ve polifenol ekstresi içeren lipozomların eldesi ve antioksidan aktivitelerinin karşılaştırılması
}

\author{
Preparation of liposomes containing vitamin C, vitamin E and polyphenol extract and \\ comparison of their antioxidant activities
}

Ziba Mokhberi OSKOUEI, Gökhan BİÇİM, A. Suha YALÇIN

\section{ÖZET}

Amaç: Çalışmamızda, antioksidan moleküllerin değişik lipozom hazırlama yöntemleri ile lipozomlanması ve lipozom yapısında iken aktivitelerini koruyup korumadıklarının incelenmesi amaçlanmıştır. Ayrıca, lipozom elde etme yöntemleri karşılaştırılarak suda ve yağda çözünen antioksidanların lipozomlanması için en uygun yöntemin belirlenmesi hedeflenmiştir.

Gereç ve Yöntemler: İnce-tabaka, dondurma-çözme, ters-faz buharlaştırma ve sonikasyon yöntemleriyle lipozom eldesi yapıldıktan sonra bu yöntemler antioksidan moleküllere uygulandı ve elde edilen sonuçlar antioksidan aktivite açısından karşılaştırıldı. Hazırlanan lipozomların karakterizasyonunda 1 şı mikroskobu, floresan mikroskop ve parçacık boyut analizöründen yararlanıldı ve lipozomların büyüklük, dağılım ve şekilleri incelendi.

Bulgular: Suda çözünür antioksidanlardan C vitamini ile polifenol ekstresi ve yağda çözünür özellikteki E vitamini değişik yöntemlerle lipozomlandı. Lipozomlanmış ve lipozomlanmamış moleküllerin ayrımı Sephadex G-25 kolon kromatografisi ile gerçekleştirildi. Elde edilen lipozomların antioksidan aktiviteleri karşılaştırıldığında aşamalı sonikasyon yöntemiyle elde edilen E vitaminli lipozomların en yüksek aktiviteye sahip olduğu bulundu.

Sonuç: Çalışmamızda kullandığımız yöntemlerden sonikasyon yöntemi en uygun yöntem olarak değerlendirildi. Bu yöntemin diğer yöntemlere göre avantajları kısa sürede sonuçlanması ve organik çözücü gerektirmemesi olarak değerlendirildi. Sonikasyon yöntemi ile hem suda çözünen hem de yağda çözünen antioksidanların lipozomlanabildiği ve antioksidanların lipozom yapısında aktivitelerini korudukları gösterildi.

Anahtar Kelimeler: Antioksidan lipozom, C vitamini, E vitamini, Polifenoller

\begin{abstract}
Objective: In this study we have used different methods for the preparation of liposomes to encapsulate antioxidant molecules and have determined whether they retain their antioxidant activities. We have compared different methods and determined the most suitable method for preparation of liposomes containing watersoluble and lipid-soluble antioxidants.

Materials and Methods: Different preparative techniques such as thin-film hydration, reverse-phase evaporation, freezethaw and periodic sonication were used to produce liposomes. These methods were used to encapsulate different antioxidant molecules and were compared for antioxidant activity. Light microscopy, fluorescence microscopy and particle size analyzers were used in order to characterize the prepared liposomes and to analyze their particle size, distribution and shape.
\end{abstract}

Results: Liposomes containing water-soluble antioxidants such as vitamin $\mathrm{C}$ and polyphenols and fat-soluble antioxidant vitamin $\mathrm{E}$ were prepared. The separation of free molecules from those that were liposomed was performed with Sephadex G-25 gel filtration chromatography. The antioxidant activity of vitamin $\mathrm{E}$ liposomes was highest in comparison to the others.

Conclusion: Among the methods we have used for preparing liposomes sonication is the fastest and also most advantageous because organic solvents such as methanol or chloroform are not used during preparation. Both water-soluble antioxidant molecules and lipid-soluble antioxidants could be prepared with this method and preserved their activities.

Keywords: Antioxidant liposome, Vitamin C, Vitamin E, Polyphenols

\section{Giriş}

Serbest radikaller diş yörüngelerinde eşleşmemiş elektron taşıyan, elektrik yüklü veya yüksüz olabilen, atom veya moleküllerdir. Yüksek enerjili olan eşleşmemiş elektronlar, çevrelerindeki eşleşmiş elektronları ayırıp onların yapılarını bozarlar. Bu durum serbest radikalleri hem tehlikeli hem de kullanışlı kılar. Yararlı etkileri arasında solunumsal patlamada, sinyal iletisinde ve çeşitli enzimsel reaksiyonlarda rol oynamaları sayılabilir. Serbest radikaller

yaşam için gereklidirler ancak oluşumları kontrolsüz bir
Ziba Mokhberi Oskouei, Gökhan Biçim, A. Suha Yalçın

Tibbi Biyokimya Anabilim Dall, Tip Fakültesi, Marmara Üniversitesi, Başıbüyük, Maltepe-İstanbul, Türkiye

e-mail:asyalcin@marmara.edu.tr

Gönderilme/Submitted: 11.05 .2014

Kabul/Accepted: 17.09 .2014 
davranış gösterirse hücre hasarına neden olurlar [1-3]. Oksijenli yaşamla birlikte aerobik organizmalarda oksijen kaynaklı radikaller oluşmaya başlamış ve bununla eş zamanlı olarak da tüm aerobik canlılarda oksidatif hasara karş1 antioksidan savunma sistemleri gelişmiştir [4,5]. Günümüzde antioksidanların lipitleri, proteinleri, nükleik asitleri ve diğer hedef makromolekülleri oksidatif hasara karşı korudukları bilinmektedir. Serbest radikal oluşumu ile antioksidan savunma arasındaki denge bozulduğunda oksidatif stres durumu ortaya çıkar.

Lipozomlar, tek veya iç-içe birçok tabakadan oluşmuş, aralarında sulu faz içeren küresel vesiküllerdir. Başlangıçta biyolojik zarların özelliklerini aydınlatmada kullanılmış olan lipozomların günümüzde başta ilaç taşıyıcı sistemler olmak üzere birçok alanda farklı kullanımları vardır. Lipozomlar lipit tabaka ve sulu faz olmak üzere iki bölümden oluşurlar. Lipit tabakanın temel yapıtaşı fosfolipitlerdir. Tek bir tabakadan oluşan lipozomlarda sulu faz içteki bölümdür. Lipozomların yapısı farklı özellikte birçok maddeyi üzerinde taşımaya uygun olduğundan kullanımları giderek artmaktadır [6-8]. Bu çalışmada antioksidan moleküllerin değişik lipozom hazırlama yöntemleri ile lipozomlanması ve lipozom yapısında aktivitelerini koruyup korumadıklarının belirlenmesi amaçlanmıştır. Ayrıca değişik lipozom elde etme yöntemleri karşılaştırılarak aralarından suda ve yağda çözünür antioksidanların lipozomlanması için en uygun yöntemin seçilmesi hedeflenmiştir.

\section{Gereç ve Yöntemler}

\section{Cihaz ve kimyasallar}

Lipozom eldesi için döner buharlaştırıcı (Heidolph Laborota 4000, Almanya), ultrasonik su banyosu (AMSCO Reliance Sonic 550, ABD), derin dondurucu (UF 401 Electrolux, İsveç) ve ekstruder (LIPEX extruder, Kanada) cihazlarından yararlanıldı. Karakterizasyon işlemlerinde mikroskop ve görüntüleme sistemi (Olympus Vannox AHBS3, Japonya), soğutmalı santrifüj (Eppendorf centrifuge 5810 R), yüksek performanslı sivi kromatografisi (Perkin Elmer Series 200, ABD), spektrofotometre (Perkin Elmer Lambda 25 UV/Vis, ABD), mikroplak okuyucu (Perkin Elmer 1420 Victor 3, ABD), parçacık boyut analizörü (Malvern Instruments Master Sizer Hydro 2000, İngiltere) ile muhtelif membran filtreler (Millipore, ABD ve Sartorius, Almanya) kullanıldı. Çalışmamızda kullanılan fosfolipitler, kolesterol, metanol, kloroform, trolox ve neocuproine Sigma-Aldrich, ABD firmasından elde edildi.

Lipozom eldesi için ince-tabaka [6], dondurma-çözme [9], ters-faz buharlaştırma [10] ve aşamalı sonikasyon

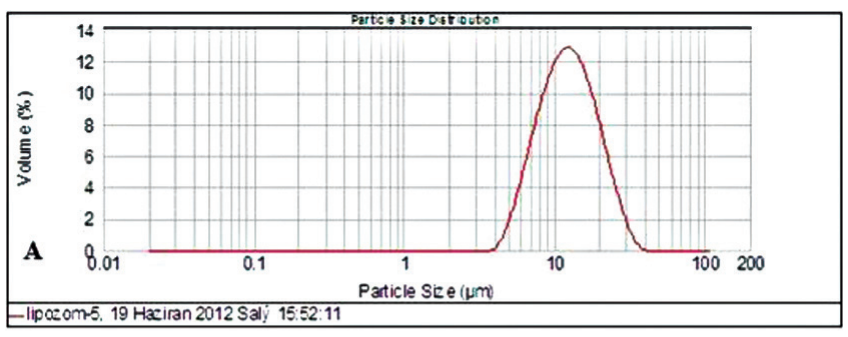

$\mathrm{D}(0.5)=12,282$

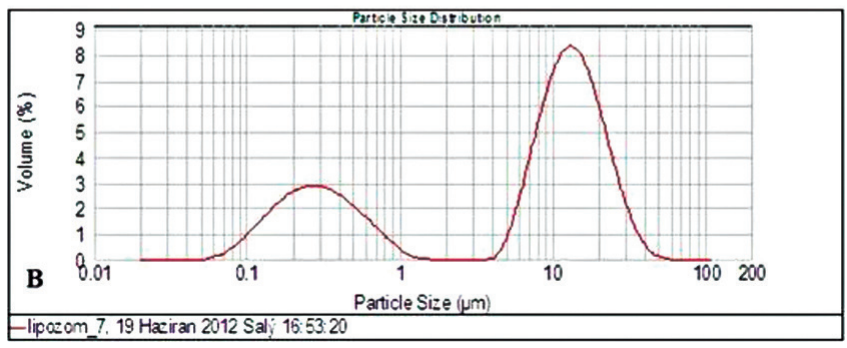

$\mathrm{D}(0.5)=9.784$

Şekil 1: İnce tabaka (A) ve dondurma-çözme (B) yöntemiyle elde edilmiş lipozomlarda boyut analizi

İnce tabaka yöntemiyle elde edilen lipozomların boyutu 4-30 mikrometre aralığında iken dondurma çözme yöntemiyle elde edilen lipozomların 0.05-1 mikrometre ve 4-30 mikrometre aralığında iki ayrı boyutta olduğu gözlendi.

$[11,12]$ yöntemleri suda ve yağda çözünen antioksidan moleküllere uygulandı ve elde edilen sonuçlar antioksidan aktivite açısından karşılaştırıldı. Lipozomların karakterizasyonunda 1şı mikroskobu, floresan mikroskop ve parçacık boyut analizöründen yararlanıldı, lipozomların büyüklüğü, dağılımları ve şekilleri incelendi.

İnce tabaka yöntemiyle lipozom eldesi: Fosfolipit ve kolesterol tartılıp kloroform içinde çözüldü. Daha sonra lipit çözeltisindeki kloroform $57-58{ }^{\circ} \mathrm{C}$ ' de vakum altında döner buharlaştırıcı (rotary evaporator) ile uçurularak lipit ince-tabakası elde edildi. Otuz dakika civarında süren bu işlem sonrasında elde edilen ince-tabaka bir gece buzdolabında bekletilerek kloroformun tamamen uçması sağlandı. Ertesi gün lipit ince-tabakası lipozomlanacak örnek içeren çözelti ile hidrate edildi. Balon içindeki lipit tabakasının tamamen çözülmesi için farklı işlemler denendi (elle veya vorteksle karıştırma, ultrasonik su banyosunda veya döner buharlaştırıcıda tutma). Yaklaşı 1 saat sonra, lipit tabakası tamamen çözülünce işlem sonlandırıldı. Balon bir gece buzdolabında bekletilerek hidratasyon işleminin tamamlanması sağlandı.

Dondurma çözme yöntemiyle lipozom eldesi: Fosfolipit ve kolesterol tartılıp 50 ml'lik plastik tüp içerisinde lipozomlanacak örnek içeren çözelti içerisinde çözüldükten sonra $-20^{\circ} \mathrm{C}$ de yaklaşık 30 dakika tutularak 

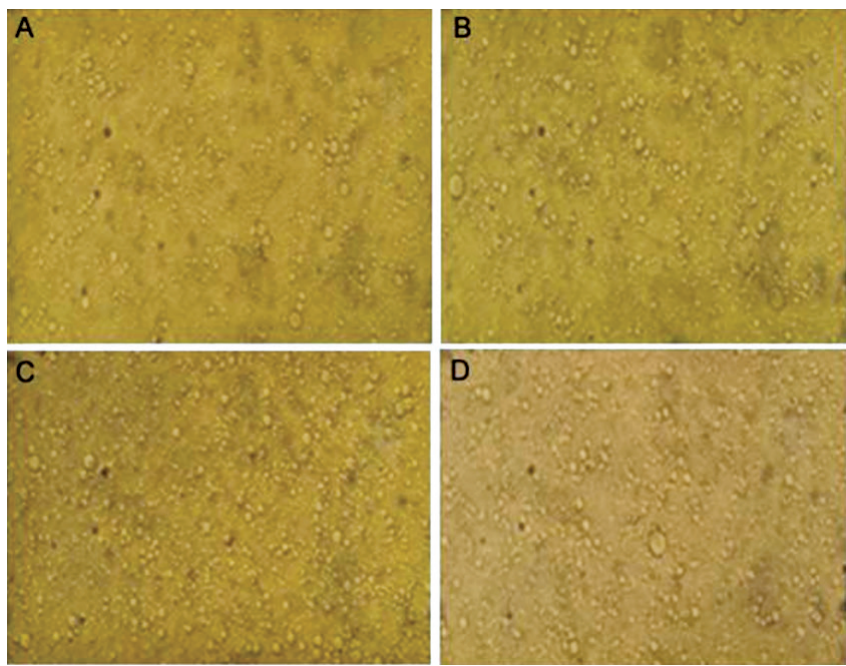

Şekil 2: Aşamalı sonikasyon ișleminin lipozom boyutlarına etkisi: Olympus Vannox AHBS3 1şı mikroskobu görüntüsü (40x)

A) Sonikasyon yok; B) 10x sonikasyon; C) 20x sonikasyon; D) 30x sonikasyon
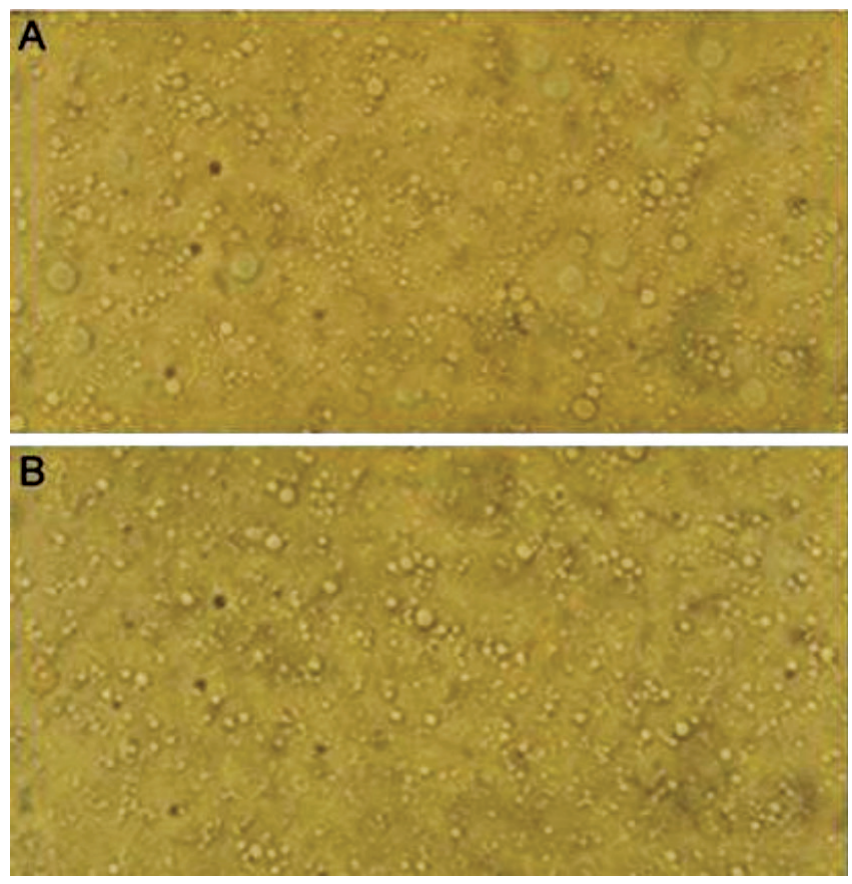

Şekil 3: Filtrasyon işleminin lipozom boyutlarına etkisi: Olympus Vannox AHBS3 1ş1k mikroskobu görüntüsü (40x)

A) Filtrasyon yok; B) $0.45 \mathrm{~mm}$ filtreden süzülmüş

ilk dondurma işlemi yapıldı. Sonraki aşamada, $37^{\circ} \mathrm{C}^{\prime}$ lik etüvde 30 dakika tutularak çözme işlemi gerçekleştirildi. $\mathrm{Bu}$ iki işlem art arda dört kez tekrarlandı. Dondurma-çözme işlemleri sonrasında çözelti $0.45 \mathrm{~mm}$ filtreden geçirildi.

Ters faz buharlaştırma yöntemiyle lipozom eldesi: Fosfolipit ve kolesterol tartılıp kloroform-metanol karışımı (2:1) içinde çözüldü. Üzerine lipozomlanması istenilen çözelti eklendikten sonra lipit çözeltisindeki kloroform ve metanol $40^{\circ} \mathrm{C}$ 'de vakum altında ve döner buharlaştırıcıda yaklaşık 15 dakikada uçuruldu.

Sonikasyon yöntemiyle lipozom eldesi: Fosfolipit ve kolesterol tartılıp üzerine lipozomlanması istenilen çözeltiden eklendi. Karışım 2 saat manyetik karıştırıcı ile karıştıııldı ve sonikasyon işlemi uygulanmak üzere tüplere ayrıldı. İlk tüpe sonikasyon yapılmazken, ikinci, üçüncü ve dördüncü tüplere sırasiyla $10,20,30 \mathrm{kez}$ sonikasyon yapıldı. Her sonikasyon basamağında 30 saniye sonikasyon yapıldıktan sonra 60 saniye ara verildi.

Antioksidan aktivite ölçümü: Suda ve yağda çözünen moleküllerin antioksidan aktiviteleri bakır iyonu indirgeme kapasitesine bağlı olarak oluşan açık mavi rengin ölçümüyle belirlendi [13]. Antioksidan aktivite Trolox eşdeğeri olarak ifade edildi, bunun için $1 \mathrm{mM}$ stok çözeltiden sulandırılarak hazırlanan çalışma standartları (0.03-1 mM) kullanıldı.

Lipozomlanmış ve lipozomlanmamış moleküllerin ayrımı: Lipozom örnekleri, $0.45 \mathrm{~mm}$ 'lik filtreden geçirildikten sonra Sephadex G-25 kromatografi kolonuna uygulandı. Elüsyon işlemi \% $0.9 \mathrm{NaCl}$ ile yapıldı, akış hızı $2 \mathrm{ml} /$ dakika olarak ayarlandı ve elde edilen fraksiyonların (1 ml) 280 nm'deki absorbansları ölçüldükten sonra elüsyon grafiği çizildi.

\section{Bulgular}

Çalışmamızda öncelikle ilk kez Bangham [6] tarafından tanımlanan ince tabaka yöntemiyle lipozom eldesi gerçekleştirildi. Daha sonra sırasıyla diğer yöntemler uygulandı. Hazırlanan lipozomların karakterizasyonunda 1şık mikroskobu, floresan mikroskop ve parçacık boyut analizöründen yararlanıldı, lipozomların büyüklüğü, dağılımları ve şekilleri incelendi ve karşılaştırıldı. Parçacık boyut analizöründen elde edilen bulgular, lipozom boyutlarının değişken ve ağılıklı olarak 1-10 $\mu \mathrm{m}$ aralığında olduğunu gösterdi (Şekil 1). Dondurma-çözme yöntemiyle hazırlanan lipozomlarda boyutların küçüldüğü ve iki farklı dağılımın olduğu görüldü. Tekrarlayan sonikasyon işleminde ise lipozom boyutlarının giderek küçüldüğü gözlendi (Şekil 2). Lipozom eldesi sırasında uygulanan filtrasyon işleminin de lipozom boyutlarını küçülttüğü belirlendi (Şekil 3).

Çalışmamızın ikinci aşamasında, antioksidan moleküllerin lipozomlanması gerçekleştirildi. Lipozomlanacak antioksidanlar, suda çözünür (hidrofilik) özellikteki C vitamini ve polifenol ekstresi ile yağda çözünür (hidrofobik) özellikteki E vitamini olarak belirlendi. Bu çalışmalarda, lipozomlanmış ve lipozomlanmamış moleküllerin ayrımı Sephadex G-25 jel 


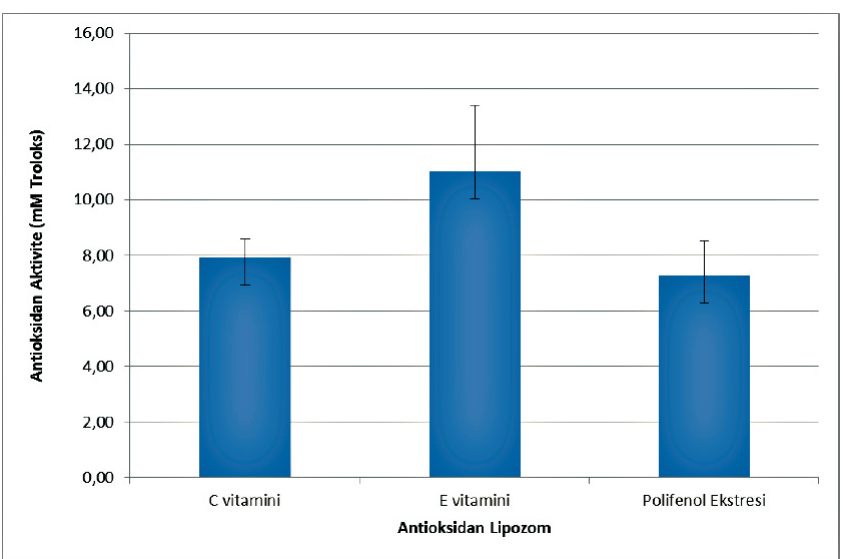

Şekil 4: C vitamini $(1 \mathrm{mM})$, E vitamini $(0.7 \mathrm{mM})$ ve polifenol ekstresi (\%1) içeren lipozomlarda antioksidan aktivite ölçümü

Aşamalı sonikasyon yöntemiyle elde edilen lipozomlarda antioksidan aktivite ölçümü CUPRAC yöntemiyle yapıldı. Sonuçlar üç ayrı deneye ait olup değerler ortalama \pm standart sapma olarak verilmiştir.

filtrasyon kromatografisi ile gerçekleştirildi. Elde edilen fraksiyonların absorbansları (A-280) ile antioksidan aktiviteleri karşılaştırıldı, E vitaminli lipozomların en yüksek aktiviteye sahip olduğu bulundu (Şekil 4).

\section{Tartışma ve Sonuç}

Antioksidan lipozom tanımı yakın zamanda ortaya çıkmış olup, yapısında suda ve/veya yağda çözünen küçük moleküllerin yanısıra antioksidan özellikteki diğer molekülleri (örn. enzim ve proteinleri) içeren lipozomlar için kullanılmaktadır [14]. Son yıllarda, antioksidan lipozomların oksidatif stres ile ilişkilendirilen bazı hastalıkların tedavisinde yararlı olabileceğine yönelik bulgular elde edilmiştir [15-17]. Lipozomlanmış antioksidan moleküllerin hardal gazının neden olduğu deri hasarlarına karşı koruyucu etkileri olduğu da ortaya konmuştur [16].

Lipozomlar, fosfolipitlerin çift tabakalı bir şekilde yerleşimiyle meydana gelen küçük (nanometre boyutunda) küresel yapılardır. Hazırlanmaları için temel olarak doğal fosfolipitler kullanılmakta olup bu moleküller hidrofilik ve lipofilik bölge içermeleriyle karakterizedir. Lipozom yapımında doğal lipitlere ek olarak sentetik lipitlerin de kullanılabilmesi stabilite açısından önemli avantajlar sağlamaktadır [18-20]. Özellikle non-iyonik surfaktanların kullanımıyla lipozomların yüksek miktarda ve çok ucuza üretilebilmeleri söz konusudur.

Öte yandan, lipozomlanan maddelerin tutulmasinda ve serbestleşmesinde maddenin fizikokimyasal özellikleri, kullanılan fosfolipitlerin cinsi, bileşimi, konsantrasyonu ve kullanılan hazırlama yöntemi etkili olmaktadır [21]. Lipozom stabilitesini arttırmak için yapıda bazı değişiklikler yapılmas1 (kolesterol eklenmesi, fosfolipit kompozisyonunun değiştirilmesi, yüzey özellikleri ve lipozom boyutlarının farklıllı̆̆ gibi) olumlu sonuçlar verebilmektedir.

Çalışmamızda lipozom eldesi için uygulanan aşamalı sonikasyon işleminin sonrasında lipozom boyutlarının küçüldüğü hem 1şık mikroskobu görüntülerinde, hem de boyut analizinde belirlendi. Lipozomlarda yeterince yüksek oranda madde tutulması başlıca amaçtır. Tutulmuş olan maddeler membran bütünlüğünün bozulmasıyla veya sızma yoluyla serbestleşirler. Serbestleşme in vivo olarak daha hızlı olmakta olup bu durum parçacık büyüklüğü ve yüzey yükü ile ilişkilidir. Ayrıca, küçük moleküllerin büyük moleküllere nazaran daha kolay serbestleştikleri bilinmektedir. Örneğin, lipozomlanmış süperoksit dismütazın deriden geçişi ile ilgili olarak yapılan bir in vitro çalışmada [22] derinin alt tabakalarına etkin geçiş için lipozom boyutları ve kolesterol içeriğinin önemli olduğu gösterilmiş̧ir.

Sonuç olarak, çalışmamızda kullandığımız aşamalı sonikasyon yönteminin diğer yöntemlere göre avantajları kısa sürede sonuçlanması ve metanol, kloroform gibi organik çözücüler içermemesi olarak değerlendirildi. Ayrıca, lipozom eldesi sırasında yapılan filtrasyon işleminin de lipozom boyutlarını küçülttügü gözlendi. Bu yöntemle hem suda çözünen hem de yağda çözünen antioksidanların lipozomlanabildiği ve antioksidanların lipozom yapısında iken aktivitelerini korudukları gösterildi.

\section{Teșekkür}

Bu çalışma Ziba Mokhberi Oskouei'nin “Antioksidan moleküllerin farklı yöntemler ile lipozomlanması" başlıklı yüksek lisans tezi kaynaklıdır ve Marmara Üniversitesi Bilimsel Araştırma Projeleri Birimi tarafından SAG-CYLP-090512-0139 numaralı proje ile desteklenmiştir.

\section{Kaynaklar}

1. Dröge W. Free radicals in the physiological control of cell function. Physiol Rev 2002; 82: 47-95.

2. Halliwell B, Gutteridge JMC. Free Radicals in Biology and Medicine. 4th ed. Oxford:Oxford University Press, 2007.

3. Li YR. Free Radical Biomedicine: Principles, Clinical Correlations, and Methodologies. Bentham Science Publishers, 2012. doi: 10.2174/97816080532231120101000i

4. Yalçın AS. Antioksidanlar. Klinik Gelişim, (Serbest Radikaller ve Antioksidanlar Özel Sayıs1), 1998; 11: 342-6.

5. Carocho M, Ferreira ICFR. A review on antioxidants, prooxidants and related controversy: Natural and synthetic compounds, screening and analysis methodologies and future perspectives. Food Chem Toxicol 2013; 51: 15-25.

6. Bangham AD. Model for biological membranes. New Sci 1971; 49: 63-4. 
7. Lasic DD. Novel applications of liposomes. Trends Biotechnol 1998; 16: 307-21.

8. Uhumwangho MU, Okor RS. Current trends in the production and biomedical applications of liposomes: a review. J Med Biomed Res 2005; 4: 9-21.

9. Ohsawa T, Miura H, Harada K. Evaluation of a new liposome preparation technique, freeze-thawing method, using L-Asparaginase as a model drug. Chem Pharm Bull 1985; 33: 2916-23.

10. Cortesi R, Esposito E, Gambarin S, Telloli P, Menegatti E, Nastruzzi C. Preparation of liposomes by reverse-phase evaporation using alternative organic solvents. J Microencapsul 1999; 16: 251-6.

11. Mueller M, Mueller-Goymann CC. Influence of temperature on the manufacturing of liposomes. Arch Pharm Med Chem 2001; 334 (Suppl. 2): 79.

12. Lapinski MM, Castro-Forero A, Greiner AJ, Ofoli RY, Blanchard GJ. Comparison of liposomes formed by sonication and extrusion: Rotational and translational diffusion of an embedded chromophore. Langmuir 2007; 23: 11677-83.

13. Apak R, Güçlü K, Özyürek M, Karademir SE, Erçağ E. The cupric ion reducing antioxidant capacity and polyphenolic content of some herbal teas. Int J Food Sci Nutr 2006; 57 : 292-304.

14. Stone WL, Smith M. Therapeutic uses of antioxidant liposomes. Mol Biotechnol 2004; 27: 217-30.
15. Hoesel LM, Flierl MA, Niederbichler AD, et al. Ability of antioxidant liposomes to prevent acute and progressive pulmonary injury. Antioxid Redox Sign 2008; 10: 973-81.

16. Paromov V, Kumari S, Brannon M, et al. Protective effect of liposome-encapsulated glutathione in a human epidermal model exposed to a mustard gas analog. J Toxicol 2011; Article ID 109516, 11 pages. doi:10.1155/2011/109516

17. Sinha J, Das N, Basu MK. Liposomal antioxidants in combating ischemia-reperfusion injury in rat brain. Biomed Pharmacother 2001; 55: 264-71.

18. Torchilin VP, Weissig V. Liposomes 2. Boston:Oxford University Press, 2003.

19. Yalçın AS, Türkoğlu M. Süt serumu proteinlerinin lipozomlanmas1. Marmara Med J 2010; 23: 22-9.

20. Crommelin DJA, Storm G. Pharmaceutical aspects of liposomes: preparation, characterization and stability. BW Müller, ed. Controlled Drug Delivery. Stuttgart: Wissenschaftlicht Verlagsgesellschaft, 1987: 80-91.

21. Bozkır A, Koçyiğit S. Lipozomların fiziksel ve kimyasal stabilitelerinin incelenmesi. Ankara Ecz Fak Der 1995; 24 : 42-52.

22. Braun E, Wagner A, Fürnschlief E, Katinger H, Vorauer-Uhl $\mathrm{K}$. Experimental design for in vitro skin penetration study of liposomal superoxide dismutase. J Pharmaceut Biomed 2006; 40: 1187-97. 